\title{
RASFF SİSTEMİNDE TAHIL VE FIRINCILIK ÜRÜNLERİNINN AFLATOKSİN VE OKRATOKSİN A DÜZEYLERİ VE HATAY YÖRESİ BUĞDAYLARININ BU MİKOTOKSİNLER AÇISINDAN DEĞERLENDİRİLMESİ*
}

\author{
Aydın Sağlam, M. Tuğrul Masatcıŏ̆lu** \\ Hatay Mustafa Kemal Üniversitesi, Ziraat Fakültesi, Gıda Mühendisliği Bölümü, Tayfur Sökmen Kampüsü, \\ Antakya, Hatay, Türkiye \\ Geliş / Received: 02.06.2021; Kabul / Accepted: 12.08.2021; Online bask1 / Published online: 13.09.2021
}

Sağlam, A., Masatcioğlu, M.T. (2021). RASFF sisteminde tahıl ve firıncllık ürünlerinin aflatoksin ve okratoksin A düzeyleri ve Hatay yöresi buğdaylarının bu mikotoksinler açısından değerlendirilmesi. GID $A$ (2021) 46 (5) 1195-1204 doi: 10.15237/gida.GD21094

Saglam, A., Masatcioglu, M.T. (2021). Analysis of RASFF notification on cereal and bakery products and evaluation of the aflatoxin and ochratoxin $A$ in wheat from Hatay region. GID $A$ (2021) 46 (5) 1195-1204 doi: 10.15237/gida.GD21094

ÖZ

Bu araştırma makalesi esas olarak iki bölüm halinde tasarlanmıştır. Öncelikle, Gıda ve Yemler için Hızlı Alarm Sistemi (RASFF) veri kaynağı kullanılarak 2009-2018 yılları arasında yapılan tahıl ve firıncilı ürünleri bildirimlerinde mikotoksin seviyeleri araştırılmıştır. Son on yllın bildirimleri değerlendirildiğinde, ortalama aflatoksin $\mathrm{B}_{1}\left(\mathrm{AFB}_{1}\right)$, toplam aflatoksin (TAF), okratoksin $\mathrm{A}(\mathrm{OTA})$ konsantrasyonları sirasiyla; 21.92, 34.98, $23.10 \mu \mathrm{g} / \mathrm{kg}$ olarak bulunmuştur. Çalışmanın ikinci bölümünde, Hatay yöresinde yetiştirilen 29 buğday örneğinde aflatoksin $\left(\mathrm{AFB}_{1}, \mathrm{AFB}_{2}, \mathrm{AFG}_{1}, \mathrm{AFG}_{2}\right)$ ve $\mathrm{OTA}$ analizi yapılmıştır. Mikotoksinlerin konsantrasyonu, HPLC-FD sistemi ile belirlenmiştir. Analitik yöntem, 401/2006 sayll EC yönetmeliğine göre valide edilmiş ve geri kazanımlar \% 83.0-107.2 aralığında saptanmıştır. $\mathrm{AFB}_{1}, \mathrm{AFB}_{2}$ ve $\mathrm{AFG}_{1}$ için pozitif örnek yüzdesi sırasıyla; \%44.8, \%13.8 ve \%27.6 bulunmuştur. Bu çalışmada en yaygin mikotoksin, 0.174$137.880 \mu \mathrm{g} / \mathrm{kg}$ aralığında olan OTA'dır (\%82.8). İncelenen numunelerin 5’inde OTA düzeyinin, Avrupa mevzuatı maksimum limit değerini ( $5 \mu \mathrm{g} / \mathrm{kg}$ ) aşı̆̆̆ tespit edilmiştir. Ayrıca, RASFF bildirimlerinde belirlenen maksimum OTA düzeyi ortalamasından üç numune daha yüksek çıkmıştır.

Anahtar kelimeler: Gıda ve yemler için hılı alarm sistemi (RASFF), buğday, aflatoksinler, okratoksin A, HPLC-FD, analitik yöntem validasyonu

\section{ANALYSIS OF RASFF NOTIFICATION ON CEREAL AND BAKERY PRODUCTS AND EVALUATION OF THE AFLATOXIN AND OCHRATOXIN A IN WHEAT FROM HATAY REGION}

\section{ABSTRACT}

This research paper was designed mainly in two parts. Primarily, the mycotoxin levels in cereal and bakery products notifications between 2009 and 2018 by using the Rapid Alert System for Food and

\footnotetext{
*Bu araştırma makalesi Aydın Sağlam'ın yüksek lisans tez çalışması kapsamında hazırlanmıştır / This paper is a part of Aydın Sağlam's MSc thesis.

${ }^{* *}$ Yazışmalardan sorumlu yazar / Corresponding author;

$\triangle$ tmasatci@gmail.com

(c) (+90) 3262455845

圆:(+90) 3262455832
}

Aydın Sağlam; ORCID no: 0000-0003-3721-7783

M. Tuğrul Masatcıoğlu; ORCID no: 0000-0002-2583-8796 
Feed (RASFF) data source were investigated. When the notifications of the last decade are evaluated, the average concentrations of aflatoxin $\mathrm{B}_{1}\left(\mathrm{AFB}_{1}\right)$, total aflatoxins (TAF), and ochratoxin A (OTA) were found $21.92,34.98$, and $23.10 \mu \mathrm{g} / \mathrm{kg}$, respectively. In the second part of the study, 29 wheat samples grown in the Hatay region of Turkey were analyzed to detect aflatoxin $\left(\mathrm{AFB}_{1}, \mathrm{AFB}_{2}, \mathrm{AFG}_{1}\right.$, $\mathrm{AFG}_{2}$ ) and OTA concentrations. The mycotoxin concentrations were determined by highperformance liquid chromatography with a fluorescence detection (HPLC-FD) system. The analytical method was validated according to Regulation (EC) No. 401/2006. The recoveries were in the range of $83.0-107.2 \%$. The percentages of positive samples for $\mathrm{AFB}_{1}, \mathrm{AFB}_{2}$ and $\mathrm{AFG}_{1}$ were $44.8,13.8$ and $27.6 \%$, respectively. In this study, the most prevalent mycotoxin was OTA $(82.8 \%)$, which found in the range of $0.174-137.880 \mu \mathrm{g} / \mathrm{kg}$. Among 5 of the studied samples, it was determined that the OTA level exceeded the European legislation maximum limit of $5 \mu \mathrm{g} / \mathrm{kg}$. Moreover, OTA levels of three samples were higher than the average of the maximum values of OTA level determined in RASFF notifications.

Keywords: Rapid Alert System for Food and Feed (RASFF), wheat, aflatoxins, ochratoxin A, HPLCFD, analytical method validation

\section{GİRIŞ}

Gıda ve Yemler için Hızlı Alarm Sistemi (Rapid Alert System For Food and Feed; RASFF), Avrupa Birliği üyesi 28 ülkenin ulusal gida güvenliği otoriteleri, Avrupa Komisyonu, Avrupa Gıda Güvenliği Otoritesi, EFSA), Avrupa Serbest Ticaret Birliği ve Norveç, Lihtenştayn, İzlanda, İsviçre arasında 1979 yllinda kurulan bir araçtır (Anonymous, 2007). Bu sistemin temel amac1, g1da ve yemlerde ciddi riskler (mikotoksinler, patojen mikroorganizmalar, pestisit kalıntıları vb.) oluşmasının sonucunda bu sistemdeki üye ülkeler arasında gida veya yem ile ilgili sağlık tehditlerine karşı daha hızlı ve koordineli bir şekilde hareket edilmesini ve alınabilecek önlemler ile ilgili yetkili kontrol birimleri arasında bilgi aktarımının sağlanmasıdır. Sistemin çalışma prensibi ise birkaç basamaktan oluşmaktadır. Öncelikle, üye ülkelerden herhangi biri insan sağlığ1 açısından gida veya yem kaynaklı olarak tehdit oluşturabilecek bir bilgiyi tespit ederse bunu sistem (RASFF) aracillğı ile Komisyon'a bildirir. İlerleyen aşamada, komisyon irtibat noktası tarafindan riskin doğrulanmasından sonra bu bildirimler belirlenen riskin ciddiyetine ve ürünün pazardaki dağılımına göre sınıflandırılır ve RASFF bildirimleri ağda bulunan tüm üyelere iletilir (Anonymous, 2007). Tehlike kategorisine göre g1dalarda en fazla RASFF bildiriminin mikotoksin kaynaklı olduğu, ülkemiz ihracatında da en önemli sorunun mikotoksin kaynaklı gidaların oluşturduğu bildirilmiştir (Sağlam ve Masatcıoğlu, 2020).
Mikotoksinler, Aspergillus, Penicillium, Alternaria, Claviceps ve Fusarium cinslerinden çeşitli küfler tarafından üretilen toksik bileşiklerdir (Marin vd., 2013). Üç yüz adet tanımlanmış ikincil metabolitler arasinda; zearalenon, deoksinivalenol, aflatoksinler, okratoksin A, patulin, fumonisinler son derece önemli mikotoksinler olarak sayılmaktadır (Amirahmadi vd., 2017). Aflatoksinler (AFs), Aspergilli türlerinden özellikle Aspergillus flavus ve Aspergillus parasiticus tarafından üretilen ikincil toksik metabolitlerdir. Bu küfler belli gida ve yemlerde uygun sıcaklık ve nem koşulları altında büyüyebilir ve hasat öncesi ve/veya sırasında, ambalajlamada, sevkiyatta ve depolamada aflatoksinler üretir (Bushby ve Wogan, 1979). Aflatoksinlerin kanserojen, mutajen ve teratojen madde potansiyeline sahip olduğu bildirilmiştir (Hendrickse, 1997). Okratoksin ise, kanserojenik, immunosupresif ve teratojenik özelliklere sahip nefrotoksik bir mikotoksin olarak tanımlanmıştır (Murphy vd., 2006). Penicillium (örneğin; Penicillium verrucosum) ve Aspergillus (örneğin; Aspergillus westerdijkiae) üyeleri tarafindan üretilen Okratoksin A (OTA)'nın, tarımsal ürünler ve buğdaydan üretilen gidalarda siklıkla bulunduğu rapor edilmiştir (Duarte vd., 2010; Lee ve Ryu, 2017).

Giray vd. (2007), Türkiye'nin farklı bölgelerinde yetiştirilen 41 buğday çeşidinde $\mathrm{AFB}_{1}, \mathrm{AFB}_{2}$, $\mathrm{AFG}_{1}$ ve $\mathrm{AFG}_{2}$ düzeylerini incelemişlerdir. Toplam aflatoksin (TAF) konsantrasyonunun 10.4-643.5 ng $/ \mathrm{kg}$ arasında değiştiği ve örneklerin $\% 59$ 'unun TAF pozitif olduğu bildirilen 
çalışmada, aflatoksin seviyelerinin yasal sınırlamaların altında olmasına rağmen bu miktarların mikotoksinlere günlük maruz kalma hususuna dikkat çekilmiştir. Trakya'nın 7 farklı bölgesinden temin edilen buğdaylarda $(n=100)$ yürütülen bir diğer araştırmada, 2'şer örneğin hem TAF hem $A_{1 F B}, 28$ buğday numunesinin ise OTA için izin verilen maksimum tolere edilebilir seviyeden yüksek olduğu rapor edilmiştir (Aydin vd., 2008). Çalışmada ayrıca, Güney-Doğu Avrupa'daki örnekleme alanında OTA varlığının dolaylı yoldan Endemik Balkan Nefropatisiyle ilişkili olduğu belirtilmekle birlikte toplum sağlığ için ciddi risk oluşturduğu ifade edilmiştir. Dolayısıyla, mikotoksinlerin tahillarda ve aynı zamanda yemlerde bulunmaları, tarım işletmelerinde kayılara neden olan ve halk sağlığını etkileyen önemli bir sorundur.

Bu çalışmanın birincil amacı, 2009-2018 yıllarını kapsayan on y1llk periyotta RASFF (Gida ve Yemler için Hızlı Alarm Sistemi)'a üye ülkelerde tahıl ve firıncllık ürünlerinde gerçekleşen mikotoksin bildirimlerinin incelenmesidir. Bir diğer anlatımla, ihracatı yapılan tahıl ve firıncilık ürünlerinde en yüksek risk grubunu oluşturan mikotoksinlerin RASFF portalında bildirimi yapılan düzeyleri saptanarak mevcut durum ortaya konulmaya çalışılmıştır. Çalışmada ayrıca, Hatay İli Antakya merkez ve çevre ilçelerinden buğday numuneleri temin edilerek, aflatoksin $\left(\mathrm{AFB}_{1}\right.$, $\mathrm{AFB}_{2}, \mathrm{AFG}_{1}, \mathrm{AFG}_{2}$ ) ve OTA seviyeleri tespit edilmiş, elde edilen bulgular hem yasal sınırlamalar (Avrupa Komisyonu; European Commission, 2006a); 2011 tarihli ve 28157 sayll Türk G1da Kodeksi Bulaşanlar Yönetmeliği'nde (Anonymous, 2011)) hem de RASFF (RASFF Portal, 2019) bildirimleri ile kiyaslanarak sunulmuştur.

\section{MATERYAL VE YÖNTEM}

\section{RASFF Bildirimlerinde Veri Materyali}

Bu çalışmada Gıda ve Yemler için Hızlı Alarm Sistemi (Rapid Alert System for Food and Feed; RASFF) veri taban1 (https://webgate.ec.europa.eu/rasffwindow/portal/) kaynak olarak kullanılmıştır (RASFF Portal, 2019). RASFF portalında primer arama tipi "gida", ürün kategorisi ise "tahıl ve firıncılık ürünleri” olarak seçilmiş ve tehlike kategorisinde "mikotoksinler" araştırma kapsamında incelenmiştir.

\section{RASFF Verilerinin Değerlendirilmesi}

RASFF portalında 01 Ocak 2009 - 31 Aralık 2018 tarihleri arasinda, RASFF sistemine üye tüm ülkelerden gelen bildirimler dikkate alınarak, yıllara göre mikotoksinlerin ( $\left.\mathrm{AFB}_{1}, \mathrm{TAF}, \mathrm{OTA}\right)$ düzeyleri Microsoft Excel (2016) programı kullanılarak değerlendirilmiştir.

\section{Buğday Numunelerinin Temini}

RASFF bildirimlerinin yanı sıra tahılların mevcut risk durumunun incelenebilmesi amaciyla, Hatay İli Antakya merkez ve çevre ilçelerindeki un fabrikaları ve değirmenlerden 2018 yll NisanMayis aylarında her biri minimum $1 \mathrm{~kg}$ olacak şekilde toplam 29 adet buğday numunesi temin edilmiştir. $\mathrm{Bu}$ örneklerin temin edilmesini takip eden iki ay içerisinde aflatoksin $\left(\mathrm{AFB}_{1}, \mathrm{AFB}_{2}\right.$, $\left.\mathrm{AFG}_{1}, \quad \mathrm{AFG}_{2}\right)$ ve OTA analizleri gerçekleştirilmiştir. Elde edilen bulgular hem Avrupa Komisyonu (European Commission, 2006a) ve Türk Gıda Kodeksi (Anonymous, 2011) tarafindan her iki mikotoksin için beyan edilen üst limitler ile hem de RASFF portalında tespit edilen verilerle karşılaştırılarak tartışılmıştır.

\section{Aflatoksin ve Okratoksin A Tayinleri Örneklem}

Toplanan buğdaylar $(n=29)$ laboratuvar ölçekli değirmende (Valsli Değirmen-4000, Bastak, Türkiye) ögütülerek $212 \mu \mathrm{m}^{\prime}$ lik elekten geçirilmiştir. Öğütme işlemi sırasında çapraz kontaminasyonu önlemek amacyyla "mikotoksin negatif buğday" her bir numuneden sonra değirmenden 5 dakika süreyle geçirilmiş ve valsler temizlenmiştir. Benzer işlem her bir numunenin elekten geçirilmesinde de uygulanmıştır. Ögütülen her numune ayrı ayrı ağzı kilitli alüminyum çeperli polietilen poşetlere (1şık ve hava geçirmez) alınarak, analizler gerçekleştirilinceye kadar $+4^{\circ} \mathrm{C}^{\prime}$ de muhafaza edilmiştir.

\section{Ekstraksiyon Yöntemi}

Aflatoksin ( $B_{1}, B_{2}, G_{1}$ ve $\left.\mathbf{G}_{2}\right)$

Un örneklerinden $\mathrm{AFB}_{1}, \mathrm{AFB}_{2}, \mathrm{AFG}_{1}$ ve $\mathrm{AFG}_{2}$ ekstraksiyonu AOAC Metod No: 999.07 de bazı 
minör değişiklikler yapılarak gerçekleştirilmiştir (AOAC, 2016). Özetle, 50 g ögütülmüş ve 212 $\mu \mathrm{m}$ 'lik elekten geçirilmiş buğday unu üzerine 300 $\mathrm{mL}$ metanol:su (4:1, v/v) ve $5 \mathrm{~g} \mathrm{NaCl}$ (analitik saflikta, Merck, Darmstad, Almanya) ilave edilerek 30 dakika blenderdan (Philips HR1337, Eindhoven, Hollanda) geçirilerek homojenize edilmiştir. Karışım kaba filtre kâğıdından süzülmüş, ekstraktan $10 \mathrm{~mL}$ alınarak üzerine 60 $\mathrm{mL}$ fosfat tamponlu tuz çözeltisinden (PBS) ilave edilmiştir. Yeni karısım önce 0.45 mikron gözenekli filtre kâğıdından, sonrasında immünoafinite kolondan (R-Biopharm Rhone Ltd, Glasgow, Scotland, İngiltere) geçirilmiştir. Örnek geçişinden sonra kolon $15 \mathrm{~mL}$ ultra saf su ile yıkanmış ve hava ile kurutulmuştur. Daha sonra kolondan sirasiyla $1.375 \mathrm{~mL}$ metil alkol (HPLC saflikta, Merck, Darmstad, Almanya) ve $1.925 \mathrm{~mL}$ HPLC saflıkta su geçirilmiş, elüat amber renkli viallere alınmışır.

\section{Okratoksin A}

Çalışma kapsamındaki un numunelerinden OTA ekstraksiyonu, R-Biopharm A20P14.V9 yöntemine göre gerçekleştirilmiştir (R-Biopharm, 2015). İlk olarak, 50 gr un numunesi $200 \mathrm{~mL}$ metanol:su (70:30, v/v) ile 1 dakika boyunca ile karıştırılmıştır. Elde edilen karışım Whatman no:4 filtre kâğıdından süzülmüş ve $10 \mathrm{~mL}$ ekstrakta 40 mL PBS eklendikten sonra cam mikrofiberlerden (Merck, Darmstad, Almanya) tekrar süzülmüştür. Toplanan 20 mL'lik ekstrakt, immünoaffinite kolonundan (R-Biopharm Rhone Ltd, Glasgow, Scotland, İngiltere) geçirilmiştir. Kolon, $10 \mathrm{~mL}$ PBS ve HPLC saflıkta $10 \mathrm{~mL}$ su ile yıkanmıştır. Son olarak OTA, $1.5 \mathrm{~mL}$ metanol ve $1.5 \mathrm{~mL}$ suyla elüe edilerek amber renkli viallere alınmıştır.

\section{Mikotoksin Analizinde HPLC Koşulları}

Aflatoksin ve OTA analizleri için kullanılan HPLC sistemi (Shimadzu, Kyoto, Japonya) LC-20 AD siv1 kromatografisi, DGU- $20 \mathrm{~A}_{3}$ degasser, CTO-20A kolon firını, SCL-10A kontrol sistemi ve LC Solution yazılımından oluşmaktadır. Mikotoksin ölçümlerinde floresans dedektör (RF10AXL) ve C18 inertsil ODS-3, $4.6 \mathrm{~mm} \times 150$ $\mathrm{mm}, 5 \mu \mathrm{m}$ kolon (GL Science, Tokyo, Japonya) kullanılmışırı. Çalışmada, kolon firın sıcaklığ 40 ${ }^{\circ} \mathrm{C}$, enjeksiyon hacmi $100 \mu \mathrm{L}$ ve akış hızı 1.000
$\mathrm{mL} / \mathrm{dk}$ olarak ayarlanmıştır. Aflatoksin $\left(\mathrm{AFB}_{1}\right.$, $\mathrm{AFB}_{2}, \mathrm{AFG}_{1}$ ve $\mathrm{AFG}_{2}$ ) için $35 \mu \mathrm{L}$ nitrik asit ve 12 $\mathrm{mg} \mathrm{KBr}$ içeren ultra saf su/metanol $(55: 45, \mathrm{v} / \mathrm{v})$ karışımı, OTA için ise asetonitril/ultra saf $\mathrm{su} /$ asetik asit (49.5:49.5:1, v/v/v) karışımı mobil faz olarak kullanılmıştır.

\section{Validasyon Yöntemi}

Bu çalışmada, 2002/657/EC sayılı Avrupa Komisyonu Kararı tarafindan bildirilen kriterlere göre; doğrusallık, hassasiyet, tespit limiti (LOD) ve tayin limiti (LOQ) belirlenmiştir (European Commission, 2002). Standart eğriler, stok çözeltilerden bilinen en az beş dilüsyonla (aflatoksinler; AFs için 0.25 ile $5 \mu \mathrm{g} / \mathrm{kg}$ ve okratoksin A; OTA için 0.25 ile $10 \mu \mathrm{g} / \mathrm{kg}$ aralığında) yapılmıştır. Geri kazanım, kontrol grubu un numunelerine (mikotoksin negatif buğday unu) yüksek ve düşük konsantrasyon seviyelerinde AFs ve OTA eklenerek on tekrarlı olacak şekilde gerçekleştirilmiştir.

\section{BULGULAR VE TARTIŞMA}

Tahıl ve Fırıncılık Ürünlerinde RASFF Portalında Belirlenen Mikotoksin Düzeyleri

Tahil ve firnncilık ürünlerinde 2009-2018 y1lları arasinda yapilan RASFF bildirimlerinde tespit edilen mikotoksin (aflatoksin $\mathrm{B}_{1} ; \mathrm{AFB}_{1}$, toplam aflatoksin; TAF ve okratoksin A; OTA) düzeyleri Çizelge 1'de verilmiştir. RASFF portalında on yıllık süreçte tahıl ve firıncılık ürünlerinde $A_{F B}$ için yapılan bildirimler incelendiğinde, $\mathrm{AFB}_{1}$ düzeyinin 2.1-251.0 $\mu \mathrm{g} / \mathrm{kg}$ aralığında değiştiği ve ortalama değerin $21.92 \mu \mathrm{g} / \mathrm{kg}$ olduğu tespit edilmiştir. Araştırmanın yapıldığı dönemde RASFF sisteminde bildirimi yapilan TAF ve OTA düzeyleri ise sirasiyla, 2.8-328.0 $\mu \mathrm{g} / \mathrm{kg}$ (ortalama; $34.98 \mu \mathrm{g} / \mathrm{kg}$ ) ve $1.0-471.0 \mu \mathrm{g} / \mathrm{kg}$ (ortalama; 23.10 $\mu \mathrm{g} / \mathrm{kg}$ ) olarak saptanmıştır.

Avrupa Komisyonu (EC: European Commission) No 1881/2006 sayll düzenlemeye (European Commission, 2006a) ve Türk Gida Kodeksi "Bulaşanlar Yönetmeliği'ne (Anonymous, 2011) göre tahıl ve tahıl ürünlerinde $A_{F B_{1}}$ en yüksek limit değerinin $2 \mu \mathrm{g} / \mathrm{kg}$, TAF için maksimum limit değerinin ise $4 \mu \mathrm{g} / \mathrm{kg}$ olduğu bildirilmiştir. Anılan her iki yönetmelikte de, OTA için maksimum limit değerinin işlenmemiş tahıllarda $5 \mu \mathrm{g} / \mathrm{kg}$, 
diğer taraftan işlenmiş tahıl ve tahıl ürünlerinde ise $3 \mu \mathrm{g} / \mathrm{kg}$ olduğu beyan edilmiştir. RASFF bildirimlerinde tespit edilen $\mathrm{AFB}_{1}$ düzeyleri beklenildiği gibi Avrupa Komisyonu tarafından bildirilen en yüksek limit değerlerinin üzerindedir. Ancak TAF düzeylerine bakıldığında, bazı yıllarda en düşük seviyelerin limit değerin altında kaldığ1 görülmektedir (Çizelge 1). Bu durum, bildirimi yapılan gida örneğinde sadece TAF değil, yanı sıra $\mathrm{AFB}_{1}$, OTA ve/veya diğer mikotoksinlerin de beyan edilmesinden kaynaklanıyor olabileceği düşünülmektedir. Örneğin, ayn1 g1da numunesinde, $\mathrm{AFB}_{1}$ değerinin en yüksek limit değerini aştı̆̆ fakat TAF değerinin sinır değeri geçmediği durumlar söz konusu olabilir. Dolayısıla, RASFF üyesi ülkeler arasında bu gida örneği için $\mathrm{AFB}_{1}$ 'den dolayı bildirim yapılmakta ve yanı sıra analiz edilen TAF değeri de beyan edilmektedir. Benzer durum OTA değerleri incelendiğinde de görülmektedir (Çizelge 1).

Çizelge 1. Tahıl ve firıncılık ürünlerinde 2009-2018 yılında yapılan RASFF bildirimlerinde tespit edilen $\mathrm{AFB}_{1}$, TAF ve OTA düzeyleri*

Table 1. AFB 1, TAF and OTA levels in cereal and bakery products notifications between 2009 and 2018 obtained by RASFF data source

\begin{tabular}{lccc}
\hline $\begin{array}{l}\text { Yillar } \\
\text { Years }\end{array}$ & $\mathrm{AFB}_{1}(\mu \mathrm{g} / \mathrm{kg})$ & $\mathrm{TAF}(\mu \mathrm{g} / \mathrm{kg})$ & OTA $(\mu \mathrm{g} / \mathrm{kg})$ \\
\hline 2009 & $9.96(2.4-47.0)$ & $14.48(2.8-51.0)$ & $6.80(3.6-18.6)$ \\
2010 & $8.80(2.6-57.0)$ & $14.07(2.9-127.0)$ & $22.23(4.9-37.0)$ \\
2011 & $27.55(2.9-155.3)$ & $27.07(3.3-153.0)$ & $12.72(4.8-39.0)$ \\
2012 & $16.24(3.2-171.4)$ & $68.30(4.9-328.0)$ & $8.91(4.5-13.0)$ \\
2013 & $24.90(3.9-86.1)$ & $23.12(6.2-57.0)$ & $97.18(5.1-471.0)$ \\
2014 & $36.67(2.6-190.0)$ & $59.00(9.5-200.0)$ & $12.53(8.9-15.0)$ \\
2015 & $55.33(2.1-251.0)$ & $77.62(10.7-284.0)$ & $19.31(1.4-40.0)$ \\
2016 & $11.09(4.5-32.5)$ & $13.50(4.5-36.5)$ & $27.55(1.0-94.8)$ \\
2017 & $9.52(3.0-54.0)$ & $20.41(5.6-67.0)$ & $7.95(6.0-9.9)$ \\
2018 & $19.12(3.6-80.2)$ & $32.27(7.5-86.5)$ & $15.80(1.2-69.0)$ \\
\hline Ortalama & $21.92(3.08-112.45)$ & $34.98(5.79-139.00)$ & $23.10(4.13-80.73)$ \\
Mean & T. & & \\
\hline
\end{tabular}

(*) Yıllara göre mikotoksin düzeyleri ortalama değer olarak verilmiştir (parantez içindeki değerler ise; minimum ve maksimum seviyeleri göstermektedir).

$\left.{ }^{*}\right)$ Mycotoxin levels by years are given as the average value (the values in parentheses show the minimum and maximum levels).

\section{Aflatoksin ve Okratoksin A için Validasyon Çalışması}

Un matrisinde AFs ve OTA için yapılan validasyon çalışması sonuçları Çizelge 2'de sunulmuştur. Kalibrasyon eğrisinin doğrusallığ1 $\left(\mathrm{R}^{2}\right) \mathrm{AFB}_{1}, \mathrm{AFB}_{2}, \mathrm{AFG}_{1}$ ve $\mathrm{AFG}_{2}$ için sirasiyla; $0.9982,0.9975,0.9953$ ve 0.9985 bulunmuştur. OTA için ise bu değer 0.9981 olarak tespit edilmiştir. $\mathrm{AFB}_{1}$ için LOD değeri $0.041 \mu \mathrm{g} / \mathrm{kg}$, LOQ değeri $0.104 \mu \mathrm{g} / \mathrm{kg}$ bulunmuştur. $\mathrm{AFB}_{2}$, $\mathrm{AFG}_{1}$ ve $\mathrm{AFG}_{2}$ için $L O D$ değerleri sırasıyla, $0.021,0.058$ ve $0.040 \mu \mathrm{g} / \mathrm{kg}$ olarak; LOQ değerleri ise sirasiyla, $0.079,0.202$ ve $0.124 \mu \mathrm{g} / \mathrm{kg}$ olarak belirlenmiştir. OTA için bu değerler sirasiyla; $0.050 \mu \mathrm{g} / \mathrm{kg}$ ve $0.166 \mu \mathrm{g} / \mathrm{kg}$ olarak tespit edilmiştir (Çizelge 2). Elde edilen sonuçlar, Kabak (2012)'in HPLC-floresans dedektör yöntemiyle gerçekleştirdiği çalışmasında, $\mathrm{AFB}_{1}, \mathrm{AFB}_{2}, \mathrm{AFG}_{1}$, $\mathrm{AFG}_{2}$ ve OTA için bulguladığı LOD-LOQ değerleri ile benzer bulunmuştur.

Bu çalışmada, tekrarlanabilirlik ve geri kazanım için standart sapma değerleri $\% 3.12$ ile $\% 12.62$ arasında değişiklik göstermiştir (Çizelge 3). Buğday unu matrisinde $\mathrm{AFB}_{1}, \mathrm{AFB}_{2}, \mathrm{AFG}_{1}$ ve $\mathrm{AFG}_{2}$ için ortalama geri kazanım değerleri 
s1rasiyla, \%99.5, \%93.8, \%98.6 ve \%89.0 olduğu tespit edilmiştir. OTA için ortalama geri kazanım değeri ise \%99.3 olarak saptanmıştır. Yüzde 89.0 ile \%99.5 arasında değişen tüm geri kazanım değerleri (Çizelge 3), Avrupa Komisyonunun 401/2006 say1l Komisyon Tüzüğü'nde (European Commission, 2006b) tanimlanan hem
$\mathrm{AFB}_{1}$ (ve TAF; $\mathrm{AFB}_{1}+\mathrm{AFB}_{2}+\mathrm{AFG}_{1}+\mathrm{AFG}_{2}$ toplamı) hem de OTA için kabul edilebilir seviyeler olan $1-10 \mu \mathrm{g} / \mathrm{kg}$ konsantrasyon aralığında $\% 70-110 ; \quad 1 \mu \mathrm{g} / \mathrm{kg}^{\prime}$ in $\quad$ altındaki konsantrasyon değerlerinde ise \%50-120 geri kazanım oranları ile uyumlu bulunmuştur.

Çizelge 2. AFs ve OTA için HPLC-FD yöntemiyle elde edilen validasyon verileri Table 2. Validation data for AFs and OTA by HPLC-FD method

\begin{tabular}{lcccc}
\hline $\begin{array}{l}\text { Mikotoksin } \\
\text { Mycotoxin }\end{array}$ & LOD $(\mu \mathrm{g} / \mathrm{kg})$ & $\begin{array}{c}\mathrm{LOQ} \\
(\mu \mathrm{g} / \mathrm{kg})\end{array}$ & $\mathrm{R}^{2}$ & $\begin{array}{c}\text { Doğrusallik Eşitliği } \\
\text { Linear regression equation }\end{array}$ \\
\hline $\mathrm{AFB}_{1}$ & 0.041 & 0.104 & 0.9982 & $\mathrm{y}=0.9991 \mathrm{x}+0.0001$ \\
$\mathrm{AFB}_{2}$ & 0.021 & 0.079 & 0.9975 & $\mathrm{y}=0.9741 \mathrm{x}-0.0026$ \\
$\mathrm{AFG}_{1}$ & 0.058 & 0.202 & 0.9953 & $\mathrm{y}=0.9908 \mathrm{x}+0.0353$ \\
$\mathrm{AFG}_{2}$ & 0.040 & 0.124 & 0.9985 & $\mathrm{y}=1.0071 \mathrm{x}-0.0145$ \\
$\mathrm{OTA}$ & 0.050 & 0.166 & 0.9981 & $\mathrm{y}=0.9981 \mathrm{x}-0.0183$ \\
\hline
\end{tabular}

Çizelge 3. HPLC-FD yöntemiyle buğday unundan AFs ve OTA geri kazanımları Table 3. The recoveries of AFs and OTA from wheat flour by HPLC-FD method

\begin{tabular}{|c|c|c|c|c|}
\hline $\begin{array}{l}\text { Mikotoksin } \\
\text { Mycotoxin }\end{array}$ & $\begin{array}{l}\text { Toksin ilavesi } \\
\text { Spiking ( } \mu \mathrm{g} / \mathrm{kg})\end{array}$ & $\begin{array}{l}\text { Geri Kazanıma }^{a} \\
\text { Recovery }(\%)\end{array}$ & $\begin{array}{c}\text { Ortalama Geri Kazanımb } \\
\text { Mean Recovery }(\%)\end{array}$ & $\begin{array}{c}\mathrm{RSD}^{\mathrm{c}} \\
(\%)\end{array}$ \\
\hline \multirow{2}{*}{$\mathrm{AFB}_{1}$} & 0.8 & 95.7 & \multirow{2}{*}{99.5} & \multirow{2}{*}{4.82} \\
\hline & 3.2 & 103.3 & & \\
\hline \multirow{2}{*}{$\mathrm{AFB}_{2}$} & 0.2 & 96.2 & \multirow{2}{*}{93.8} & \multirow{2}{*}{3.12} \\
\hline & 0.8 & 91.6 & & \\
\hline \multirow{2}{*}{$\mathrm{AFG}_{1}$} & 0.8 & 90.6 & \multirow{2}{*}{98.6} & \multirow{2}{*}{8.67} \\
\hline & 3.2 & 107.2 & & \\
\hline \multirow{2}{*}{$\mathrm{AFG}_{2}$} & 0.2 & 94.6 & \multirow{2}{*}{89.0} & \multirow{2}{*}{9.62} \\
\hline & 0.8 & 83.0 & & \\
\hline \multirow{2}{*}{ OTA } & 3.0 & 98.2 & \multirow{2}{*}{99.3} & \multirow{2}{*}{12.62} \\
\hline & 10.0 & 104.9 & & \\
\hline
\end{tabular}

(a) Geri kazanım değerleri 10 tekrarın ortalamasıdır.

(b) Tüm geri kazanım değerleri ortalaması.

(c) RSD; bağıl standart sapma.

(a) Recovery was means of 10 replicates.

(b) Overall average recovery.

(c) RSD; Relative standard deviation

\section{Hatay Yöresi Buğdaylarının Mikotoksin Düzeyleri}

Bu çalışmada Hatay İli merkez (Antakya) ve çevre ilçelerinde bulunan değirmen ve un fabrikalarından toplanan buğday numuneleri öğütülerek unda; aflatoksin $\left(\mathrm{AFB}_{1}, \mathrm{AFB}_{2}, \mathrm{AFG}_{1}\right.$, $\mathrm{AFG}_{2}$ ) ve OTA varlığ1 araştırılmış ve elde edilen sonuçlar Çizelge 4'de verilmiştir.

Çalışmada LOQ değerinin üzerinde tespit edilen tüm örnekler, pozitif olarak değerlendirilmiştir.
Buna göre toplam 29 un numunesinde test edilen aflatoksinler (AFs) içerisinde, $\mathrm{AFB}_{1}(\% 44.8)$ en yaygın görünen mikotoksin olarak saptanmış, bunu sirasiyla; $\mathrm{AFG}_{1}(\% 27.6)$ ve $\mathrm{AFB}_{2}$ (\%13.8)'nin takip ettiği görülmüştür (Çizelge 4). Analiz edilen buğday örneklerinde $\mathrm{AFG}_{2}$ ye rastlanmamıştır. Çalışmada $\mathrm{AFB}_{1}$ konsantrasyonu ortalama $0.246 \mu \mathrm{g} / \mathrm{kg}(0.136-0.484 \mu \mathrm{g} / \mathrm{kg})$ olarak belirlenmiş (Çizelge 4) olup, LOQ değeri ile Avrupa Komisyonu maksimum limit değerleri arasında (0.104-2.000 $\mu \mathrm{g} / \mathrm{kg}) 13$ buğday unu 
örneğinde (\%44.8) $\mathrm{AFB}_{1}$ tespit edilmiştir (Çizelge 5). Çalışmada Avrupa Komisyonu (European Commission, 2006a) ve Türk Gida Kodeksi (Anonymous, 2011)'ne göre tahıl ve tahil ürünlerinde $\mathrm{AFB}_{1}$ maksimum limit değerinin (2 $\mu \mathrm{g} / \mathrm{kg}$ ) üstünde herhangi bir örnek tespit edilmemiştir. Dört buğday ununda $\mathrm{AFB}_{2}(0.090$ $0.190 \mu \mathrm{g} / \mathrm{kg}), 8$ numunede ise $\mathrm{AFG}_{1}(0.216-0.540$ $\mu \mathrm{g} / \mathrm{kg}$ ) saptanmıştır. Analiz edilen örnekler $\mathrm{AFB}_{1}$ yönünden RASFF bildirimlerinde tespit edilen düzeylerle (Çizelge 1) kıyaslandığında, oldukça düşük bulunmuştur.

Çizelge 4. Buğday unu örneklerinde tespit edilen AFs ve OTA düzeyleri

Table 4. AFs and OTA concentration in wheat flour samples

\begin{tabular}{|c|c|c|c|}
\hline \multirow{2}{*}{$\begin{array}{l}\text { Mikotoksin } \\
\text { Mycotoxin }\end{array}$} & \multirow{2}{*}{$\begin{array}{l}\text { Pozitif Örnek } \mathrm{n}(\%) \\
\text { Positive samples } n\end{array}$} & \multicolumn{2}{|c|}{$\begin{array}{c}\text { Konsantrasyon }(\mu \mathrm{g} / \mathrm{kg}) \\
\text { Concentration }\end{array}$} \\
\hline & & $\begin{array}{l}\text { Ortalamab } \\
\text { Mean }\end{array}$ & $\begin{array}{l}\text { Değer Aralı̆̆ } 1^{c} \\
\text { Range }\end{array}$ \\
\hline $\mathrm{AFB}_{1}$ & $13(44.8)$ & 0.246 & $0.136-0.484$ \\
\hline $\mathrm{AFB}_{2}$ & $4(13.8)$ & 0.135 & $0.090-0.190$ \\
\hline $\mathrm{AFG}_{1}$ & 8 (27.6) & 0.354 & $0.216-0.540$ \\
\hline $\mathrm{AFG}_{2}$ & \multicolumn{3}{|c|}{ Tüm örneklerde $\mathrm{AFG}_{2}$ değerleri <LOQ olarak tespit edilmiştir } \\
\hline OTA & $24(82.8)$ & 17.785 & $0.174-137.880$ \\
\hline \multicolumn{4}{|c|}{$\begin{array}{l}\text { (a) Pozitif örnek: Tayin limiti (LOQ) değerlerinin }\left(\mathrm{AFB}_{1} \text { için } 0.104 \mu \mathrm{g} / \mathrm{kg}, \mathrm{AFB}_{2} \text { için } 0.079 \mu \mathrm{g} / \mathrm{kg}, \mathrm{AFG}_{1} \text { için } 0.202 \mu \mathrm{g} / \mathrm{kg}, \mathrm{AFG}_{2}\right. \\
\text { için } 0.124 \mu \mathrm{g} / \mathrm{kg} \text { ve OTA için } 0.166 \mu \mathrm{g} / \mathrm{kg} \text { ) üstünde kalan örnek sayls1 } \\
\text { (b) Pozitif örneklerin ortalama konsantrasyon değerleri } \\
\text { (c) Pozitif örneklerin minimum ve maksimum değerleri } \\
\text { (a) Positive samples: The samples which are over the limit of quantification (LOQ); } 0.104 \mu \mathrm{g} / \mathrm{kg} \text { for } A F B_{1} ; 0.079 \mu \mathrm{g} / \mathrm{kg} \text { for AFB }, 0.202 \mu \mathrm{g} / \mathrm{kg} \\
\text { for AFG1, } 0.124 \mu \mathrm{g} / \mathrm{kg} \text { for AFG } \text { and } 0.166 \mu \mathrm{g} / \mathrm{kg} \text { for } O T A \\
\text { (b) Average concentration of positive samples } \\
\text { (c) Min. and max. values of positive samples }\end{array}$} \\
\hline
\end{tabular}

Çizelge 5. Buğday unu örneklerinde AFs ve OTA dağılımı

Table 5. Distribution of $A F s$ and OTA in wheat flour samples

\begin{tabular}{|c|c|c|c|c|c|}
\hline \multirow{2}{*}{$\begin{array}{l}\text { Mikotoksin } \\
\text { Mycotoxin }\end{array}$} & \multicolumn{5}{|c|}{$\begin{array}{l}\text { Örneklerin mikotoksin dağıllımı n }(\%) \\
\text { Samples' distribution of mvcotoxin n }\end{array}$} \\
\hline & $<\mathrm{LOD}^{a}$ & LOD-LOQ $^{\mathrm{b}}$ & LOQ-Limitc & Limit-RASFFe & $>$ RASFFe \\
\hline $\mathrm{AFB}_{1}$ & $16(55.2)$ & - & $13(44.8)$ & - & - \\
\hline $\mathrm{AFB}_{2}$ & 14 (48.3) & $11(37.9)$ & $4(13.8)^{d}$ & - & - \\
\hline $\mathrm{AFG}_{1}$ & $15(51.7)$ & $6(20.7)$ & $8(27.6)^{d}$ & - & - \\
\hline $\mathrm{AFG}_{2}$ & $22(75.9)$ & $7(24.1)$ & - & - & - \\
\hline OTA & $5(17.2)$ & - & $19(65.6)$ & $2(6.9)$ & $3(10.3)$ \\
\hline
\end{tabular}

(a, b) Mikotoksinlerin LOD ve LOQ değerleri Çizelge 2'de verilmiştir

(c) Avrupa Komisyonu (EC, 2006) ve TGK “Bulaşanlar Yönetmeliği’ne (Anonim, 2011) göre, tahıl ve tahıl ürünlerinde AFB maksimum limit değeri $2 \mu \mathrm{g} / \mathrm{kg}$ olduğu bildirilmiştir. Yönetmelikte, OTA maksimum limit değerinin işlenmemiş tahıllarda 5 $\mu \mathrm{g} / \mathrm{kg}$, işlenmiş tahıl ve tahıl ürünlerinde ise $3 \mu \mathrm{g} / \mathrm{kg}$ olduğu bildirilmiştir.

(d) Yasal düzenlemeler ile $\mathrm{AFB}_{2}$ ve $\mathrm{AFG}_{1}$ için maksimum limit değeri belirlenmemiştir. Dolayısıyla bu sütunda anılan mikotoksinler için >LOQ örnek sayısı verilmiştir.

(e) RASFF sisteminde bildirimi yapılan $\mathrm{AFB}_{1}$ ve OTA mikotoksinlerinin ortalama düzeyleri Çizelge 1'de verilmiştir.

(a,b) LOD and LOQ values of mycotoxins are given in Table 2

(c) According to European Commission (EC, 2006) and Turkish Food Codex (Anonymous, 2011) "Contaminants Regulation", the maximum permitted levels of $A F B_{1}$ is $2 \mu \mathrm{g} / \mathrm{kg}$ for all cereals and products derived from cereals, including processed cereal products. In the regulation, it is stated that the OTA maximum limit value is $5 \mu \mathrm{g} / \mathrm{kg}$ in unprocessed cereals and $3 \mu \mathrm{g} / \mathrm{kg}$ in processed cereal products and cereals intended for direct buman consumption.

(d) There is no set up maximum permitted levels for $A F B_{2}$ and $A F G_{1}$ by $E U$ regulations in all cereals and products derived from cereals. Therefore, the number of samples are given as $>L O Q$ for both mycotoxins.

(e) The average levels of $A F B_{1}$ and OTA mycotoxins reported in the $R A S F F$ system are given in Table 1. 
Bakırc1 (2014) çalışmasında 21'i buğday ve buğday temelli ürünler olmak üzere toplam 24 adet tahıl ürününde yapmış olduğu aflatoksin analiz sonuçlarının, ölçüm limitlerinin altında olduğunu bildirmiştir. Bir başka araştırmada, Türkiye'nin farklı bölgelerinden toplanan 41 adet buğday numunesinde toplam AF düzeyi 10.4-643.5 ng/ kg arasında belirlenmiştir (Giray vd., 2007). Araştırmacılar bu değerlerin Türkiye'de TAF için izin verilen limit değerin altında olmasına rağmen, test edilen örneklerin \%59'unun aflatoksin ile kontamine olduğunu rapor etmişlerdir. Çalışmada ayrıca, $\mathrm{AFB}_{1}, \mathrm{AFB}_{2}, \mathrm{AFG}_{1}$ ve $\mathrm{AFG}_{2}$ için pozitif örnek oran1 sirasiyla, $\% 42, \% 12, \% 37$ ve $\% 12$ olarak bildirilmiştir (Giray vd., 2007). ELISA yöntemi kullanılarak yapılan bir diğer çalışmada, Trakya'nın 7 farklı bölgesinden toplanan 100 buğday unu numunesinin \%45'inde TAF (0.05$14.01 \mu \mathrm{g} / \mathrm{kg}$; ortalama: $0.79 \mu \mathrm{g} / \mathrm{kg}$ ), \%20'sinde $\mathrm{AFB}_{1}$ (ortalama: $0.48 \mu \mathrm{g} / \mathrm{kg}$ ) ve \%81'inde OTA $(2.07 \mu \mathrm{g} / \mathrm{kg}$ ) tespit edilmiştir (Aydin vd., 2008). $\mathrm{Bu}$ örneklerin \%2'sinde hem TAF hem de $\mathrm{AFB}_{1}$ düzeyleri TGK ve Avrupa Komisyonu tarafindan bildirilen sınır değerlerinin (sırasıyla; 4 ve $2 \mu \mathrm{g} / \mathrm{kg}$ ) üzerinde olduğu rapor edilmiştir.

Çizelge 4 incelendiğinde, analiz edilen örnekler arasinda en yaygin mikotoksinin \%82.8'lik oranla $(24 / 29)$ OTA olduğu görülmektedir. Pozitif olarak nitelendirilen numunelerin OTA düzeyleri, $0.174-137.880 \mu \mathrm{g} / \mathrm{kg}$ aralığında tespit edilmiş, ortalama değer ise $17.785 \mu \mathrm{g} / \mathrm{kg}$ olarak belirlenmiş̧tir (Çizelge 4). Test edilen örneklerin 19'unda, diğer bir ifadeyle \%65.6'sinda OTA değerleri, LOQ ile limit değerleri arasinda tespit edilmiştir (Çizelge 5). Beş numunede ise, Avrupa Komisyonu (European Commission, 2006a) ve Türk Gıda Kodeksi (Anonymous, 2011)'ne göre işlenmemiş tahıllar için OTA en yüksek sınır değeri olan $5 \mu \mathrm{g} / \mathrm{kg}^{\prime \prime n}$ üstünde saptanmıştır. Bu örneklerin \%10.3'ü; on ylllk dönemde (20092018 y1lları arasinda) RASFF bildirimlerinde tespit edilen OTA düzeylerinin ortalamasından da yüksek bulunmuştur (Çizelge 5).

Karagözlü ve Karapınar (2000), aşurelik buğday, misır, misır unu, yulaf gevreği, yulaf ezmesi, yulaf unu ve müsliden oluşan toplam 100 adet gida örneğinde OTA taraması yapmış ve analiz edilen örneklerin \%4'ünde OTA (0.27-9.84 $\mu \mathrm{g} / \mathrm{kg}$ arasında) belirlemişlerdir. Trakya bölgesinde yapılan bir araştırmada, toplanan 100 buğday unu numunesinin \%28'inde OTA'nın izin verilen limit değerinden yüksek bulunduğu rapor edilmiştir (Aydin vd., 2008). Ancak araştırmada her ne kadar buğday unu ile çalışıldığı bildirilmiş olsa da, elde edilen bulgular Türk Gıda Kodeksi Bulaşanlar Yönetmeliği’nde işlenmemiş tahıllar için belirtilen üst limit değeri $(5 \mu \mathrm{g} / \mathrm{kg})$ ile değil; işlenmiş tahıl ve tahıl ürünleri için verilen üst limit değeri (3 $\mu \mathrm{g} / \mathrm{kg}$ ) ile kıyaslanmıştır. Dolayısıyla, çalışmada bildirilen yaklaşık üç buğday unu örneğinden birinde OTA varllğının tespit edilmiş olması bu duruma bağlı olabilir. Bir diğer araştırmada, analiz edilen 25 adet misır ve misir bazlı ürünlerde $17.79-126.2 \mu \mathrm{g} / \mathrm{kg}$ düzeyinde, 34 adet buğday ve buğday temelli ürünlerde ise, $2.02-3.56 \mu \mathrm{g} / \mathrm{kg}$ düzeyinde OTA tespit etmiştir (Bakırc1, 2014). Çalışmada tahıl ve tahıl bazlı ürünlerin \%6'sında OTA tespit edilirken, toplam analizi yapilan 67 örneğin \%3’ünün Türk Gida Kodeksi'ne göre belirlenen kabul edilebilir sınırların üstünde olduğu rapor edilmiştir.

Literatür incelendiğinde, ülkemizde tahıl ve firıncilık ürünlerinde OTA'nın hem sağlık açısından hem de ticari olarak önemli bir problem olduğu açıkça görülmektedir. Bu araştırmada elde edilen veriler, geçmiş ylllardan günümüze OTA kaynaklı bu problemin süregeldiğini açıkça ortaya koymaktadır.

\section{SONUÇ}

Araştırmanın ilk aşamasında tahıl ve firıncılık ürünlerinde mikotoksin riski hakkında genel bir durum değerlendirmesi yapmak amaciyla, 20092018 yıllarını kapsayan dönemde RASFF sistemine üye tüm ülkelerden gelen bildirimler dikkate alınarak, yllara göre aflatoksin ve OTA düzeyleri incelenmiştir. Elde edilen bulgular değerlendirildiğinde, yllar içerisinde bildirimi yapılan $\mathrm{AFB}_{1}, \mathrm{TAF}$ ve OTA düzeyleri her ne kadar farklılık göstermiş olsa da, son yıllarda bu mikotoksinlerin tahıl ve firıncllık ürünleri için hâlâ yüksek bir risk teşkil ettiği açıkça görülmektedir.

Çalışmanın ikinci aşamasında ise, Hatay İli merkez (Antakya) ve çevre ilçelerde bulunan değirmen ve 
un fabrikalarından toplanan buğdaylarda aflatoksin ve OTA varllğ̆1 araştırılmış, bulgular hem yasal sinirlamalar ile hem de RASFF bildirimlerinde tespit edilen düzeyler ile kıyaslanmıştır. Analiz edilen 29 buğday numunesinde $\mathrm{AFB}_{1}$ değerlerinin; Avrupa Komisyonu (European Commission, 2006a) ve Türk Gıda Kodeksi Bulaşanlar Yönetmeliğ̣i'ne (Anonymous, 2011) göre, tahıl ve tahillardan üretilmiş ürünlerdeki maksimum limit değerinin altında kaldığı tespit edilmiştir. Bu buğday numunelerinin 5'inde ise, OTA düzeylerinin yukarıda anılan her iki yönetmelik tarafindan bildirilen maksimum limit değerini $(5 \mu \mathrm{g} / \mathrm{kg})$ aştığ1 belirlenmiştir. Elde edilen bulgular 2009-2018 yılları arasında tahıl ve firıncllı ürünlerinde yapilan RASFF bildirimlerinde tespit edilen OTA düzeylerinin maksimum değerlerinin ortalaması $(80.73 \mu \mathrm{g} / \mathrm{kg}$ ) ile kiyaslandığında 3 buğday örneğinde (\%10.3) bu değerin üzerinde bulunduğu tespit edilmiştir. Özetle, araştırma sonuçları değerlendirildiğinde, buğday numunelerinde OTA'nın primer olarak sağlık açısından dahası ticari olarak önemli bir problem olduğu açıkça görülmektedir.

Firıncılık ürünlerinde OTA tespitinin en önemli nedenlerinden biri, hammadde olarak kullanilan tahılların bu mikotoksin ile bulaşı halinde olmasıdır. Fırıncılık ürünlerinin pişirilmesi esnasında OTA düzeyinin sadece beşte bir oranında azaldığı, bir diğer ifadeyle, bu mikotoksinin son üründe dikkate değer bir düzeyde kaldığ1 göz önünde bulundurulursa, tarladan-sofraya tahılların muhafaza koşullarının iyileştirilmesi ve gerekli denetimlerin arttırılması önem arz etmektedir. Ayrıca, konuyla ilgili üreticiler, tahıl işletmeleri ve tüketici farkındalığını arttırmaya yönelik çalışmalar yürütülmelidir.

\section{ÇIKAR ÇATIŞMASI BEYANI}

Yazarlar, çıkar çatışması olmadığını beyan eder.

\section{YAZAR KATKILARI}

AS, makalenin metodoloji, biçimsel analiz, yazma-orijinal taslak ve görselleştirmesine katk1 sunmuştur. MTM, kavramsallaştırma, metodoloji, biçimsel analiz, yazma-orijinal taslak, yazmainceleme ve düzenleme, görselleştirme ve danışman olarak katkı sağlamıştır. Yazarlar makalenin son halini okudu ve onayladi.

\section{KAYNAKLAR}

Amirahmadi, M., Shoeibi, S., Rastegar, H., Elmi, M., Mousavi Khaneghah, A. (2017). Simultaneous analysis of mycotoxins in corn flour using LC/MS-MS combined with a modified QuEChERS procedure. Toxin Reviews, 1-9.

Anonymous (2011). Türk Gida Kodeksi Bulaşanlar Yönetmeliği. Gida, Tarım ve Hayvancilık Bakanlığı. 29 Aralık 2011 tarih ve 28157 sayllı Resmî Gazete, Ankara.

Anonymous (2007). The Rapid Alert System for Food and Feed (RASFF) Annual Report 2007. https://ec.europa.eu/food/sites/food/files/safe ty/docs/rasff_annual_report_2007_en.pdf,

(Accessed: 06 May 2019).

AOAC (2016). AOAC (999.07). Official Methods of Analysis AOAC INTERNATIONAL. 20th Edition, Washington DC.

Aydin, A., Gunsen, U., Demirel, S. (2008). Total Aflatoxin, Aflatoxin $\mathrm{B}_{1}$ and Ochratoxin A levels in Turkish Wheat Flour. J Food Drug Anal, 16(2): 48-53.

Bakırc1, G.T. (2014). Tahıl ve Tahıl Ürünlerinin Aflatoksin, Okratoksin A, Zearalenon, Fumonisin ve Deoksinivalenol Mikotoksinleri Yönünden İncelenmesi. Akademik Gıda, 12 (2): 46-56.

Bushby, W.F., Wogan, G.N. (1979). Food-borne mycotoxins and alimentary mycotoxicoses. In: Food-borne infections and intoxication, Riemann, H., Bryan, F.L. (chief ed.), Academic Press, New York, pp. 519-610.

Duarte, S.C., Pena, A., Lino, C.M. (2010). A review on ochratoxin A occurrence and effects of processing of cereal and cereal derived food products. Food Microbiol, 27: 187-198.

European Commission (2002). Commission regulation (EC) No 657/2002 of 17 August 2002 council directive 96/23/EC concerning the performance of analytical methods and the interpretation of results. Official Journal of the European Communities, L 221, 8-36. 
European Commission (2006a). Commission regulation (EC) No 1881/2006 of 19 December 2006 setting maximum levels for certain contaminants in foodstuffs. Official Journal of the European Union, L 364, 5-23.

European Commission (2006b). Commission regulation (EC) No 401/2006 of 23 February 2006 laying down the methods of sampling and analysis for the official control of the levels of mycotoxins in foodstuffs. Official Journal of the European Union, L 70, 12-34.

Giray, B., Girgin, G., Engin, A.B., Aydın, S., Sahin, G. (2007). Aflatoxin levels in wheat samples consumed in some regions of Turkey. Food Control, 18: 23-29.

Hendrickse, R.G. (1997). Of sick turkeys, kwashiorkor, malaria, prenatal mortality, heroin addicts and food poisoning: research on the influence of aflatoxins on child health in the tropics. Annals of Tropical Medicine and Parasitology, 91: 787-793.

Kabak, B. (2012). Determination of aflatoxins and ochratoxin A in retail cereal products from Turkey by high performance liquid chromatography with fluorescence detection. Food Control, 28: 1-6.
Karagözlü, N., Karapınar, M. (2000). Bazı Tahıl ve Ürünlerinde Okratoksin-A ve Fungal Kontaminasyon. Turk J Biol, 24, 561-572.

Lee, H.J., Ryu, D. (2017). Worldwide occurrence of mycotoxins in cereals and cereal derived food products: Public health perspectives of their cooccurrence. J Agric Food Chem, 65(33): 7034-7051.

Marin, S., Ramos, A.J., Cano-Sancho, G., Sanchis, V. (2013). Mycotoxins: Occurrence, toxicology, and exposure assessment. Food Chem Toxicol, 60: 218-237.

Murphy, P.A., Hendrich, S., Landgren, C., Bryant, C.M. (2006). Food mycotoxins: an update. J Food Sci, 71(5): 51-65.

RASFF Portal (2019). The Rapid Alert System for Food and Feed (RASFF) Portal Search Page. https://webgate.ec.europa.eu/rasff-

window/portal/ (Accessed: 06 May 2019).

R-Biopharm (2015). Ochraprep application methods. Art. No A20P14.V9. Glasgow, Scotland, UK: RBiopharm Rhone Ltd.

Sağlam, A., Masatcioğlu, M.T. (2020). Avrupa Birliği ve Türkiye kaynaklı gıdalarda 2009-2018 y1lları arasinda RASFF bildirimleri. GID A (2020) 45(4) 623-634 doi: 10.15237/gida.GD20051. 